\title{
Phytopathology"
}

\section{Trichoderma Species: Versatile Plant Symbionts}

\author{
Paulina Guzmán-Guzmán, María Daniela Porras-Troncoso, Vianey Olmedo-Monfil, ${ }^{\dagger}$ and Alfredo Herrera-Estrella ${ }^{\dagger}$
}

First and third authors: Departamento de Biología, DCNyE Campus Guanajuato, Universidad de Guanajuato, Noria Alta s/n. CP 36050, Guanajuato, Gto., México; and second and fourth authors: Laboratorio Nacional de Genómica para la Biodiversidad-Unidad de Genómica

Avanzada, Cinvestav. Km 9.6 Libramiento Norte Carretera Irapuato-León, CP 36824, Irapuato, Gto., México.

Accepted for publication 1 November 2018.

\begin{abstract}
Because of the need to provide food for the growing population, agricultural activity is faced with the huge challenge of counteracting the negative effects generated by adverse environmental factors and diseases caused by pathogens on crops, while avoiding environmental pollution due to the excessive use of agrochemicals. The exploitation of biological systems that naturally increase plant vigor, preparing them against biotic and abiotic stressors that also promote their growth and productivity represents a useful and viable strategy to help face these challenges. Fungi from the genus Trichoderma have been widely used in agriculture as biocontrol agents because of their mycoparasitic capacity and ability to improve plant health and protection against phytopathogens, which makes it an excellent plant symbiont. The mechanisms employed by Trichoderma include secretion of effector molecules and secondary metabolites that mediate the beneficial interaction of Trichoderma with plants, providing tolerance to biotic and abiotic stresses. Here we discuss the most recent advances in understanding the mechanisms employed by this opportunistic plant symbiont as biocontrol agent and plant growth promoter. In addition, through genome mining we approached a less explored factor that Trichoderma could be using to become successful plant symbionts, the production of phytohormones-auxins, cytokinins, abscisic acid, gibberellins, among others. This approach allowed us to detect sets of genes encoding proteins potentially involved in phytohormone biosynthesis and signaling. We discuss the implications of these findings in the physiology of the fungus and in the establishment of its interaction with plants.
\end{abstract}

The world population is approaching 8 billion people, which imposes on us the challenge of ensuring food provision and energy resources, both of which depend on plants. Moreover, it has been estimated that by 2050 the world's population will swell to 9.7 billion. We will need to increase food production by 50 to $100 \%$ for the expected world's population while facing another major challenge, climate change, which is predicted to increase the scale and frequency of emerging plant diseases. In this scenario, it is evident that we require more sustainable agricultural systems that allow significant yield increases and improved quality, while reducing the negative impact of agrochemicals on the environment.

An attractive alternative to secure food production is the use of plant-growth promoting microorganisms. The beneficial effects of microbes on plants depend on complex chemical signaling processes affected by soil type, nutritional state, and climate factors (López-Bucio et al. 2015). In this regard, plant roots release a

${ }^{\dagger}$ Corresponding authors: V. Olmedo-Monfil; E-mail: vg.olmedo@ugto.mx, and A. Herrera-Estrella; E-mail: alfredo.herrera@cinvestav.mx

Funding: Research conducted by the group of V. Olmedo-Monfil related to the topics of this review was supported by grants CONACyT CB-286709 and UGDAIP $142 / 2018$

(C) 2019 The American Phytopathological Society number of compounds that affect composition of the microbiota present in the rhizosphere, leading to the establishment of the interactions (Ortíz-Castro et al. 2009). Such symbioses involve plant growth promoting bacteria and fungi, considered natural biostimulants.

Beneficial plant-microbe associations result in more effective nutrient uptake, improved growth and development, and frequently higher tolerance to biotic and abiotic stress (Schirawski and Perlin 2018; Stringlis et al. 2018). Therefore, they help increase crop growth and yield. In addition, plant growth promoting microorganisms are capable of inducing plant defense systems (Jayaraman et al. 2014).

Microorganisms improve plant nutrient uptake, as in the case of mycorrhiza (Plett et al. 2014) or nodule forming bacteria (Igiehon and Babalola 2018), improving plant growth and development (Behie and Bidochka 2014; Igiehon and Babalola 2018). Nonmycorrhizal fungi like Metarhizium anisopliae can also improve nitrogen uptake by the plant, mobilizing nitrogen from the insect it parasitizes to the plant roots, resulting in increased nitrogen availability (Behie et al. 2012).

Beneficial microbes can also act as biocontrol organisms, helping plants defend themselves from attack by pathogens. This is the case for fungi of the genus Trichoderma, which are excellent mycoparasites of plant pathogens, directly protecting plants against them (Benítez et al. 2004). In addition, Trichoderma spp. can also enhance 
the plant defense system through priming, enabling the plant to respond in a much faster and stronger manner to pathogen attack (Beckers et al. 2009; Hermosa et al. 2012; Malmierca et al. 2015). This implies, beneficial microbes can modulate the plant defense system to enable the interaction (Hassani et al. 2018; Jayaraman et al. 2014), like pathogens do through manipulation of the salicylic acid (SA) and/or jasmonic acid (JA) pathways (Berens et al. 2017; Genre and Russo 2016). Not only can manipulation of the JA and SA pathways help establishment of the interaction, but also phytohormones such as auxins, cytokinins (CKs), ethylene (Et), abscisic acid (ABA), and gibberellins (GAs) modulate the relationship between the plant and the beneficial microbe (Van der Ent et al. 2009; Zamioudis and Pieterse 2012). Hormonal modulation is implicated not only in plant defense and beneficial interactions, but in general it controls plant growth and development. Plants require a fine-tuned hormonal balance to grow, develop, reproduce and deal with biotic and abiotic stresses.

Organisms other than plants, particularly soil bacteria and some fungi, have the capacity to produce auxins, CKs, GAs, ABA, and Et. The possible biological role, biosynthesis and applications of fungal phytohormones has been thoroughly reviewed by Tudzynski and Sharon (2002), and more recently by Chanclud and Morel (2016). These authors propose that the hormones could be involved in growth, hyphal or haustoria development, or conidial germination, and that they could also be important during interaction with plants, and not necessarily related to fungus-plant interactions, as some of these hormones are also produced by fungi that are not known to interact with plants (Chanclud and Morel 2016).

Trichoderma species have adapted to a plethora of ecosystems, where they play a major role in ecosystem health. These fungi are frequently predominant components of the mycoflora in native and agricultural soils, colonize plant roots, in some cases aerial parts of the plant and can even grow as endophytes. Nevertheless, the commercial success of Trichoderma species, with more than $60 \%$ of registered biopesticides based on formulations containing at least one strain of the genus is based on their capacity as necrotrophic mycoparasites that sense, invade, and destroy other fungi (Mukherjee et al. 2013). Furthermore, fungi belonging to the genus Trichoderma are well known for their capacity to stimulate plant growth and development, as well as their ability to increase plant tolerance to abiotic and biotic stress (López-Bucio et al. 2015). Here we discuss the most recent advances in understanding the mechanisms employed by these opportunistic plant symbionts as biocontrol agents and plant growth promoters.

\section{MYCOPARASITISM BY TRICHODERMA}

The mycoparasitic interaction of Trichoderma with other filamentous fungi is apparently programmed by host signals (Mukherjee et al. 2013), resulting in the production of infective structures and enzyme secretion (Fig. 1). In vitro, the first detectable interaction between Trichoderma and its host is the chemotropic growth of the hyphae of the mycoparasite toward its prey, which is likely a response to diffusible signals such as oligochitins (Chet et al. 1981; Cortes et al. 1998). Once the mycoparasite reaches the host, its hyphae often coil around it or attach to it by forming hooklike structures (Fig. 1). Several decades ago, it was proposed that penetration of the host mycelium takes place by partial degradation of its cell wall (Elad et al. 1983). Later, it was proven that indeed, Trichoderma secretes a complex set of membrane and cell wall degrading enzymes (CWDEs) (Carsolio et al. 1994; Geremia et al. 1993; Vázquez-Garcidueñas et al. 1998). Those observations, eventually, led to the identification of the first mycoparasitismrelated genes, which respond transcriptionally to the presence of a fungal prey (Carsolio et al. 1994; Geremia et al. 1993). Most mycoparasitism-related genes described so far encode CWDEs, which are considered to act synergistically with secondary metabolites and proposed to be determinant in the antagonistic capacity of Trichoderma (Schirmbock et al. 1994).

The genome sequences of three species of the genus revealed the richness of genes encoding secondary metabolite biosynthesis pathways and CWDEs required to kill a prey or defend from it (Kubicek et al. 2011). At a genomic scale, the necessity to degrade the prey's cell wall is reflected in the abundance of chitinase and $\beta$-1,3-glucanase encoding genes present in the Trichoderma genome compared with other fungi (Kubicek et al. 2011). The family of enzymes involved in chitin degradation is strongly expanded in Trichoderma, particularly in T. virens and T. atroviride, which contain the highest number of genes encoding chitinolytic enzymes of all described fungal genomes (Kubicek et al. 2011). In fact, a recent phylogenomic analysis of hypocrealean fungi (including nine Trichoderma spp.) revealed that the genus Trichoderma likely evolved from an ancestor that fed on either fungi or arthropods. The analysis revealed that the monophyletic family Hypocreaceae, shared a last common ancestor with entomoparasitic

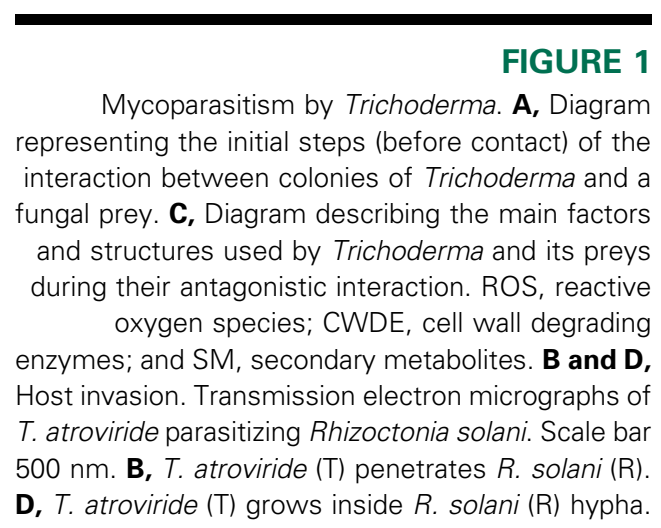

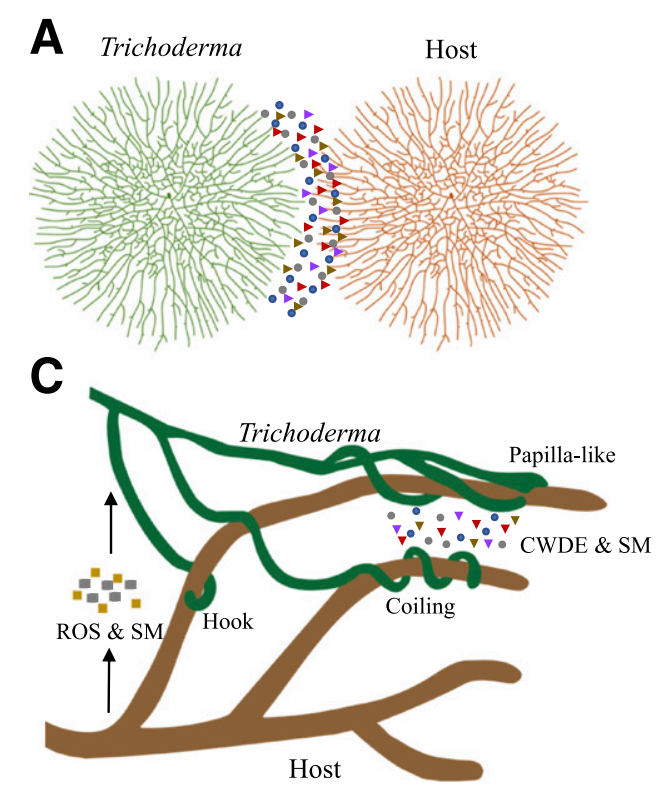
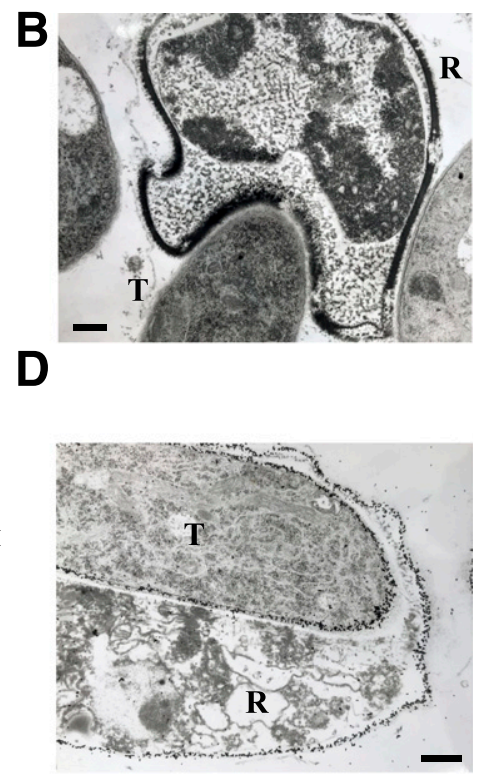
fungi (Druzhinina et al. 2018). Interestingly, mycoparasitism by Trichoderma shows very important parallels to insect pathogenicity by species of Metarhizium, perhaps the best understood group of entomopathogenic fungi, in terms of signals leading to the production of CWDEs, the battery of enzymes they produce, and the regulation of their expression (Geremia et al. 1993; Carsolio et al. 1994; Freimoser et al. 2005; Hu and St. Leger 2004). Furthermore, it was recently discovered that as in the case of Trichoderma, some species of Metarhizium are rhizosphere competent and establish beneficial interactions with plants (Behie et al. 2012; Khan et al. 2012; Sasan and Bidochka 2013).

Another class of genes relevant to mycoparasitism are those involved in the synthesis of secondary metabolites, processes for which at least three of the Trichoderma genomes sequenced (T. atroviride, T. reesei, and T. virens) contain a varying assortment of genes coding for nonribosomal peptide synthetases (NRPS) and polyketide synthases (PKS). T. virens contains the highest number of NRPS (28), compared with 19 and 16 in its closest competitors Fusarium graminearum and $T$. atroviride, respectively. Interestingly, half of the secondary metabolite gene clusters present in $T$. virens and $T$. atroviride, considered effective mycoparasites, are not present in the T. reesei genome (Kubicek et al. 2011).

The advent of genomic technologies fostered genome wide gene expression analyses. In this regard, an EST-based analysis of gene expression during the interaction of $T$. atroviride with Botrytis cinerea/Rhizoctonia solani allowed the identification of 66 genes that were overexpressed during the onset of mycoparasitism (Seidl et al. 2009). The most abundant genes were involved in posttranslational processing and amino acid metabolism and included components of the stress response reaction to nitrogen shortage, signal transduction and lipid catabolism. Interestingly, in that analysis only a few genes encoding CWDEs were up-regulated during the early stages of mycoparasitism. Two of them encoded proteases, which was interpreted as indicating a possible major involvement of proteases in the first stages of mycoparasitism as key factors liberating molecules that would signal the presence of a fungal prey.

Using a high-throughput transcriptome analysis, 175 genes from T. atroviride were identified that responded to the presence of $R$. solani. In agreement with the observations made by Seidl and coworkers (2009), functional annotation of the responsive genes indicated that the most abundant group of genes up-regulated during direct contact with the prey was metabolism. Further analysis confirmed that 13 genes tested, including those encoding an expansinlike protein (swo1), acetyl xylan esterase (axe1), aspartyl protease ( response to the presence of $R$. solani (Reithner et al. 2011).

A comparative transcriptomic analysis of T. atroviride, T. virens, and $T$. reesei revealed a strikingly different response prior to physical contact with the host hyphae. T. atroviride expressed a set of genes involved in production of secondary metabolites, $\beta$-glucanases, various proteases and small secreted cysteine rich proteins, while $T$. virens expressed the genes necessary for gliotoxin biosynthesis. Interestingly, T. reesei increased the expression of genes involved in cellulose degradation (Atanasova et al. 2013). Thus, the weapons used by different Trichoderma species and even isolates are different, which may be used as a major feature for the development of biofungicides.

\section{TRICHODERMA-PLANT INTERACTIONS}

Trichoderma improves plant growth and development in axenic conditions but also in the field on a variety of crops (Hermosa et al. 2012; Mukherjee et al. 2013). In this regard, the fungal mycelium secretes compounds that promote root branching, thus improving nutrient and water acquisition (Garnica-Vergara et al. 2016). In addition, Trichoderma species can modulate the plant defense systems, interacting with the different signaling pathways involved. It is well understood that modulation of the SA pathway enables the establishment of the interaction between T. harzianum and A. thaliana, where SA restricts the amount of colonized root tissue by $T$. harzianum (Alonso-Ramírez et al. 2014). Nonetheless, fungi like $T$. atroviride can finely modulate both SA and JA pathways to promote resistance (Salas-Marina et al. 2011).

Communication between Trichoderma and plants involves secreted proteins as key factors, as it has been observed in plantpathogen/mycorrhizae interactions. Recent analyses have shown that the Trichoderma genomes encode hundreds of potential effector proteins (Guzmán-Guzmán et al. 2017; Mendoza-Mendoza et al. 2018; Nogueira-López et al. 2018). In a few cases, the role of effectors in the establishment of the Trichoderma-root association has been experimentally demonstrated. Protein profiles, determined from maize root tissue in interaction with $T$. virens show that, in addition to effectors, $T$. virens secrets products related to secondary metabolism, that help the fungus in scavenging reactive oxygen species and hydrolysis of the plant cell wall (Nogueira-López et al. 2018).

From the predicted secretome, we demonstrated the differential expression of genes with predicted functions corresponding to different families during the Trichoderma-plant interaction. Among them tatrx 2 from $T$. atroviride, which encodes a thioredoxin. Thioredoxins play important roles as effectors, inhibiting apoptotic processes mediated by stress-activated MAPK signaling cascades (Lee et al. 2005; Rivas et al. 2004). tatrx2 could play a role in mediating the beneficial interaction between Arabidopsis and T. atroviride, inducing plant resistance. We also found differential expression of the $T$. atroviride tacfeml gene, encoding a CFEM (common in fungal extracellular membrane) protein; these proteins are involved in appressorium formation in Magnaporthe oryzae, previously known as Magnaporthe grisea (Kulkarni et al. 2003). The tvlysml and talysml genes of T. virens and T. atroviride, respectively, encoding members of the LysM repeats family, were also differentially expressed during the Trichoderma-Arabidopsis interaction. LysM proteins play roles in pathogenic systems binding chitin oligomers from the fungus, avoiding recognition by the plant and favoring colonization (De Jonge and Thomma 2009), so that in Trichoderma they could increase its plant association capacity. Finally, tvhydiil, encoding a class II hydrophobin from T. virens, is involved in the plant colonization process (GuzmánGuzmán et al. 2017).

Another interesting possibility that could explain how Trichoderma manipulates the plant is through the production of phytohormones. Therefore, for this review, we searched among the $T$. atroviride genome for genes that could participate in the biosynthesis and signaling of molecules like SA or JA, and other phytohormones. We used as seed the A. thaliana protein sequences involved in biosynthesis and signaling of the SA, JA, auxins, CKs, GAs, Et, and ABA pathway in BLASTP against the database of the T. atroviride genome (v.2.0). Coupled to this approach, we selected some of the sequences that showed the highest percentage of similarity for each protein and, performed BLASTP against the genomes of the basal plants Physcomitrella patens and Marchantia polymorpha. Similarly, we performed BLASTP analyses using fungal and bacterial proteins, which function in phytohormone synthesis is supported by experimental evidence (Table 1). Interestingly, the only pathway for which we found no orthologs was that involved in JA biosynthesis.

\section{PRIMING OF PLANT DEFENSE RESPONSES}

The molecular basis of systemic resistance (ISR) induced by $T$. hamatum in A. thaliana has been analyzed by microarrays. Treatment with $T$. hamatum accelerated activation of the defense response against $B$. cinerea, which was interpreted as ISR-boost, 
and confirmed using mutants affected in various defense-related pathways (Mathys et al. 2012). Similarly, Morán-Diez et al. (2012) analyzed $A$. thaliana gene expression changes when exposed to T. harzianum, they detected changes in genes related to both biotic and abiotic stress responses, involving several signal transduction pathways controlled by phytohormones. Their data support the hypothesis that SA- and JA-related genes were downregulated in A. thaliana in the presence of T. harzianum, while several genes related to abiotic stress responses were upregulated. Accordingly, they hypothesized that at an early stage of the interaction the plant defenses mediated by JA and SA are reduced, allowing root colonization. Thus, Trichoderma was not perceived as a threat by the host plant, while upon longer exposure to Trichoderma defense responses would be activated both locally and systemically.

Given that effector proteins could be responsible for the activation of the plant defense response, the role of some of them has been examined in detail. The $T$. virens hydrophobin-like protein Sm1 induces systemic disease resistance in cotton and maize against Colletotrichum spp., while its T. atroviride ortholog (Epl1), confers protection in tomato plants against $A$. solani and $B$. cinerea. This protection correlates with the expression of genes associated with the JA defense response, or with those genes encoding enzymes with peroxidase and an $\alpha$-dioxygenase activity (Djonovic et al. 2007; Salas-Marina et al. 2015). In addition to Sm1 and Epl1, their paralogs Sm2 and Ep12, seem to be important for the Trichoderma-maize interaction, enhancing protection and reducing leaf lesion size caused by Cochliobolus heterostrophus (Gaderer et al. 2015). Similarly, the hydrophobin HYTLO1 from T. longibrachiatum induces the expression of genes related to the SA- and JA-mediated defense pathways, enhancing protection in tomato and pepper against B. cinerea (Ruocco et al. 2015), and the $T$. asperellum swollenin TasSwo induces the expression of defense-related genes in cucumber plants (Brotman et al. 2008).

Some other Trichoderma nonproteinaceous molecules have the capacity to induce plant defense systems. The secondary metabolite harzianolide from T. harzianum, increased the expression of marker genes related to both JA/Et- and SA-mediated defense pathways in tomato (Cai et al. 2013).

Effector proteins and secondary metabolites are thus thought to be relevant in the establishment of the Trichoderma-plant symbiosis, and in triggering plant defense responses by activating the production of SA and/or JA. Nevertheless, it is possible that in addition to the release of protein effectors, Trichoderma might directly deliver these signaling molecules.

Salicylic acid. Salicylic acid (SA) is a small phenolic compound involved in many plant physiological processes; it functions as a signal molecule during plant defense, mediating one of the major defenses against biotrophic fungi. In plants, there are two SA biosynthesis pathways: the isochorismate pathway (IC), and the phenylpropanoid pathway (PAL), both pathways initiate with chorismate as precursor, which is the final product of the shikimate pathway (Seyfferth and Tsuda 2014). IC synthase (ICS or SID2) is a key enzyme that catalyzes the first step of the IC pathway, converting chorismate into isochorismate; while PAL is the enzyme that catalyzes the first step in the phenylpropanoid pathway, converting phenylalanine into cinnamic acid (Seyfferth and Tsuda 2014). We found two genes in the T. atroviride genome encoding enzymes with putative phenylalanine ammonia-lyase (ID 260476) and isochorismate synthase activity (ID 297768) (Table 1). According to our search, T. atroviride could synthesize SA, through either the PAL and/or the IC pathway.

\section{PLANT GROWTH STIMULATION}

The efficacy of Trichoderma spp. as biofertilizers has gained support from multiple reports indicating that when applied to soil, seeds, or plant surfaces, it increases the solubility of nutrients as well as the nutrient uptake capacity of the root. The beneficial effect of Trichoderma on plants can be explained by the capacity of the fungus to modulate root architecture and/or through the production of compounds that increase nutrient availability, such as siderophores and organic acids (reviewed in López-Bucio et al. 2015).

Phytohormones produced by fungi have recently been shown to play important roles in pathogenic fungus-plant interactions. However, information on their participation in beneficial fungusplant interactions is scarce.

Auxins. Auxins are a group of compounds derived from indole that in plants regulate cell division and elongation, and root initiation, to mention some of their biological roles. Some phytopathogenic fungi like Fusarium spp., Rhizoctonia spp., and Colletotrichum gloeosporioides have been identified as auxin producing fungi, primarily affecting spore germination and cell elongation (Chanclud and Morel 2016; Tudzynski and Sharon 2002). In Phycomyces blakesleeanus, exogenous application of auxins increased the growth rate of the fungus, and the growing zone of the sporangiophore, indicating that auxins play a physiological role in this organism (Živanović et al. 2018).

Biosynthesis of auxins in plants is very complex, and is divided in two major types, tryptophan (Trp)-independent and Trp-dependent pathways (Mano and Nemoto 2012). Four pathways have been proposed as Trp-dependent that lead to the biosynthesis of IAA: (i) the YUCCA (YUC); (ii) the indole-3 pyruvic acid (IPA); (iii) the indole-3 acetamide (IAM); and (iv) the indole-3-acetaldoxime (IAOx) pathways (Mano and Nemoto 2012; Mashiguchi et al. 2011). In fungi auxin biosynthesis has been shown to take place through the IAM in Fusarium sp. and C. gloeosporioides, and the IPA pathway in Ustilago sp. and Rhizoctonia sp. (Kochar et al. 2011; Chanclud and Morel 2016).

T. virens can produce at least two auxin related compounds, indole-3-acetic acid (IAA) and indole-3-acetaldehyde (IAAld), through a Trp-dependent pathway, which led to the proposal that auxin production regulates plant root architecture (ContrerasCornejo et al. 2009). However, the proposed role of auxins synthesized by the fungus and regulation of root architecture is still in debate (Hoyos-Carvajal et al. 2009; Nieto-Jacobo et al. 2017), since changes in root architecture are also promoted by volatile organic compounds produced by several Trichoderma strains (Fig. 2) (Nieto-Jacobo et al. 2017). In fact, there is evidence that the volatile 6-pentyl-2H-pyran-2-one (6-PP) produced by $T$. atroviride provokes changes in root architecture, increasing plant biomass through auxin signaling in Arabidopsis (GarnicaVergara et al. 2016). To determine beyond doubt the role of auxins in the Trichoderma-plant interaction, it is essential to test mutants affected in auxin synthesis.

We identified in the T. atroviride genome 10 genes with orthologs in A. thaliana or U. maydis that play a role in auxin biosynthesis or signaling, including genes putatively involved in the IAM and IPA pathways (Table 1). These auxin biosynthesis pathways have been characterized in Fusarium and Ustilago. In the Fusarium sp. genome, Tsavkelova et al. (2012) found a gene cluster with one indole-3-acetamide hydrolase and one tryptophan monooxygenase encoding gene and showed that the IAM pathway is fully functional in $F$. proliferatum ET1. We found two sequences in T. atroviride encoding a putative IAM hydrolase (ID 316778 and 30057) and a tryptophan amino transferase (transaminase) (Table 1) (ID 149780). In $U$. maydis, two indole-3-acetaldehyde dehydrogenase genes are involved in IAA production via indole-3-pyruvic acid (Reineke et al. 2008). For this pathway in T. atroviride we found one sequence (ID 138587) with its best hit to an A. thaliana flavin monooxygenase encoding gene, and one (ID 141294) encoding a protein with putative aldehyde oxidase and xanthine dehydrogenase functions (Table 1). The presence of these sequences in the T. atroviride genome suggests that these fungi can synthesize auxins, through the 
IPA pathway, as previously reported by Contreras-Cornejo et al. (2009), or via the IAM pathway. Although we found some genes encoding enzymes related to the other two biosynthesis pathways, the pathways appear incomplete.

In Arabidopsis, auxin transport is mediated by four main protein families: (i) auxin resistance (AUX1), (ii) pin formed (PIN); (iii) pin-like (PILS); and (iv) ATP-binding cassette B (ABCB) (Feraru et al. 2012; Křeček et al. 2009). Whereas, auxin signaling is mediated by four different protein families: (i) auxin response factor (ARF); (ii) auxin-indole-3-acetic acid (AUXIAA); (iii) transport inhibitor response-auxin signaling f-box protein (TIR/AFB); and (iv) auxin binding protein 1 (ABP1) (Finet et al. 2013). A BLAST search using Arabidopsis auxintransport genes as query allowed the identification of genes related to auxin transport of the AUX1, PILS, and ABCB families in the P. blakesleeanus genome, but none related to the PIN family (Živanović et al. 2018). We found that the T. atroviride genome contains three sequences (IDs 297344, 297671, and 146579) with the predicted function of GTP-binding ADP-ribosylation factor and GTP-binding ADP-ribosylation factor-like protein, related to the Arabidopsis ARF3 gene (Table 1). The fact that we found genes involved in auxin biosynthesis and signaling in the $T$. atroviride genome suggests that Trichoderma may not only produce auxins, but that the fungus may also be able to perceive them. Thus, auxins could actually play a role in the physiology of the fungus, regardless of its interaction with the plant.

Cytokinins (CKs). CKs are hormones involved in plant cell differentiation, root and shoot branching, stress tolerance, and nutrient balance (Müller and Sheen 2007). CKs are important in the establishment of plant-microbe interactions and defense. CKs when applied exogenously to A. thaliana induce resistance to the pathogen Hyaloperonospora arabidopsidis. Cytokinins may also function as priming agents because when plants are treated with them and no pathogen challenge is presented there is no defense activation, activation only occurs upon pathogen infection (Albrecht and Argueso 2017). Several reviews regarding priming by beneficial fungi indicate a role of various Trichoderma species in activating plant defenses (Balmer et al.

TABLE 1

Trichoderma atroviride genes putatively involved in phytohormone synthesis and signaling pathways

\begin{tabular}{|c|c|c|c|c|}
\hline Hormone & JGI catalog ID & Molecular function in Trichoderma & $\%$ Identity & $\%$ Similarity \\
\hline Auxins & $\begin{array}{l}138587 \\
141294 \\
316778 \\
54776 \\
297344 \\
297671 \\
146579 \\
30057 \\
149780 \\
154814\end{array}$ & $\begin{array}{l}\text { Flavin-containing monooxygenase } \\
\text { Aldehyde oxidase and xanthine dehydrogenase, molybdopterin binding } \\
\text { Amidase } \\
\text { Cytochrome P450, E-class, group I } \\
\text { GTP-binding ADP-ribosylation factor Arf1 } \\
\text { GTP-binding ADP-ribosylation factor-like protein ARL1 } \\
\text { GTP-binding ADP-ribosylation factor Arf6 (dArf3) } \\
\text { Aldehyde dehydrogenase } \\
\text { Aromatic amino acid aminotransferase and related proteins } \\
\text { Pyruvate decarboxylase/indole pyruvate decarboxylase }\end{array}$ & $\begin{array}{l}32 \\
32 \\
36 \\
25 \\
59 \\
60 \\
55 \\
49 \\
27 \\
25\end{array}$ & $\begin{array}{l}49 \\
49 \\
50 \\
39 \\
78 \\
75 \\
75 \\
66 \\
44 \\
44\end{array}$ \\
\hline Abscisic acid & $\begin{array}{l}158420 \\
141294 \\
80521 \\
295125 \\
28537 \\
129592\end{array}$ & $\begin{array}{l}\text { Short-chain-dehydrogenase/reductase } \\
\text { Aldehyde oxidase, Xanthine oxidase activity } \\
\text { Cytochrome P450, E-class, group IV } \\
\text { Cytochrome P450, E-class, group I } \\
\text { Putative reductases/dehydrogenases with broad range of substrate } \\
\text { specificities } \\
\text { Cytochrome P450, E-class, group IV }\end{array}$ & $\begin{array}{l}37 \\
32 \\
34 \\
38 \\
45 \\
27\end{array}$ & $\begin{array}{l}50 \\
49 \\
56 \\
57 \\
65 \\
43\end{array}$ \\
\hline Gibberellins & $\begin{array}{l}160158 \\
160158 \\
293815 \\
293815 \\
156885 \\
302240 \\
284926 \\
143946\end{array}$ & $\begin{array}{l}\text { Geranylgeranyl pyrophosphate synthase } \\
\text { Geranylgeranyl pyrophosphate synthase } \\
\text { Cytochrome P450, E-class, group IV } \\
\text { Cytochrome P450, E-class, group IV } \\
\text { Cytochrome P450, E-class, group IV } \\
\text { Gibberellin oxidase } \\
\text { Polyprenyl synthetase } \\
\text { Hydroxymethylglutaryl-CoA reductase }\end{array}$ & $\begin{array}{l}39 \\
35 \\
35.4 \\
34 \\
30.5 \\
75 \\
34 \\
73\end{array}$ & $\begin{array}{l}55 \\
55 \\
56 \\
51 \\
50 \\
83 \\
47 \\
83\end{array}$ \\
\hline Ethylene & $\begin{array}{c}301763 \\
297477 \\
39146 \\
238874 \\
301763 \\
301763 \\
301802\end{array}$ & $\begin{array}{l}\text { S-adenosylmethionine synthetase } \\
\text { 1-Aminocyclopropane-1-carboxylate synthase } \\
\text { Iron/ascorbate family oxidoreductases } \\
\text { 1-Aminocyclopropane-1-carboxylate deaminase } \\
\text { S-Adenosylmethionine synthetase } \\
\text { S-Adenosylmethionine synthetase } \\
\text { 2OG-Fe(II) oxygenase }\end{array}$ & $\begin{array}{l}80.5 \\
41.3 \\
45.2 \\
95 \\
61 \\
61 \\
35\end{array}$ & $\begin{array}{l}91 \\
59 \\
55 \\
98 \\
76 \\
75 \\
53\end{array}$ \\
\hline Salicylic acid & $\begin{array}{l}260476 \\
297768\end{array}$ & $\begin{array}{l}\text { Phenylalanine ammonia-lyase } \\
\text { Isochorismate synthase }\end{array}$ & $\begin{array}{l}41 \\
26\end{array}$ & $\begin{array}{l}60 \\
44\end{array}$ \\
\hline Cytokinins & $\begin{array}{l}278239 \\
134727 \\
134727\end{array}$ & $\begin{array}{l}\text { tRNA isopentenyltransferase } \\
\text { Putative lysine decarboxylase family } \\
\text { Possible lysine decarboxylase }\end{array}$ & $\begin{array}{l}64 \\
40 \\
42\end{array}$ & $\begin{array}{l}79 \\
57 \\
59\end{array}$ \\
\hline & $\begin{array}{c}148265 \\
286374 \\
88129 \\
255011\end{array}$ & $\begin{array}{l}\text { Protein-histidine kinase activity } \\
\text { Protein-histidine kinase activity } \\
\text { Two-component response regulatory activity } \\
\text { Adenosine kinase activity }\end{array}$ & $\begin{array}{l}32 \\
39 \\
30 \\
43\end{array}$ & $\begin{array}{l}49 \\
62 \\
51 \\
64\end{array}$ \\
\hline & & & \multicolumn{2}{|c|}{ (Continued on next page) } \\
\hline
\end{tabular}


2015; Shoresh et al. 2010). Nevertheless, in ectomycorrhizal mycelia, CKs promote hyphal branching (Barker and Tagu 2000); and in $M$. oryzae, CKs help the fungus tolerate oxidative stress (Chanclud et al. 2016).

Cytokinin biosynthesis in plants begins with isopentenyl transferase (IPT) or tRNA-IPT, using dimethylallyl-diphosphate (DAMPP) as substrate, being $\mathrm{N}^{6}-\left(\Delta^{2}\right.$-isopentenyl) adenosine-5' - triphosphate and -diphosphate ribonucleotides (iPRTP and iPRDP, respectively) the products of this first step. Later, cytochrome P450 monooxygenases (CYP735A1 and CYP735A2) convert both products to transzeatin ribonucleotides (tZRTP/tZRDP). Finally, the active CK forms are obtained by the LONELY GUY (LOG) family of enzymes (Simm et al. 2016). In Magnaporthe oryzae (Chanclud et al. 2016) and Claviceps purpurea (Hinsch et al. 2015), the putative IPT and LOG genes have been characterized, and both fungi are capable of producing CKs.

We identified six genes in T. atroviride that in Arabidopsis, Marchantia polymorpha, or $C$. purpurea are related to CK signaling or biosynthesis. Five of the six genes are related to $\mathrm{CK}$ biosynthesis, with putative, tRNA isopentenyl transferase, LOG or lysine decarboxylase activities (Table 1). Thus, the $T$. atroviride genome encodes the main enzymes required for CK biosynthesis (IDs 278239 and 134727), suggesting that this fungus produces CKs.

In A. thaliana, there are at least three receptors involved in plant CKs signaling: histidine kinase 2 (AHK2), histidine kinase 3 (AHK3), and histidine kinase 4 (AHK4/CRE1/WOL) (Hirose et al. 2008). In T. atroviride we found two genes (IDs 148265 and 286374) encoding proteins with predicted proteinhistidine kinase activity with high similarity to the Arabidopsis AHK2 and AHK4 proteins, and other sequences with predicted response regulatory activity (ID 88129) and adenosine kinase activity (ID 255011), similar to the Arabidopsis ARR4 and ADHK2 proteins, which are also involved in CKs signaling (Table 1).

One of the sequences related to CK biosynthesis has an ortholog in the genome of $C$. purpurea (Table 1) (ID 278239), which is known to produce CKs (Hinsch et al. 2015). These findings

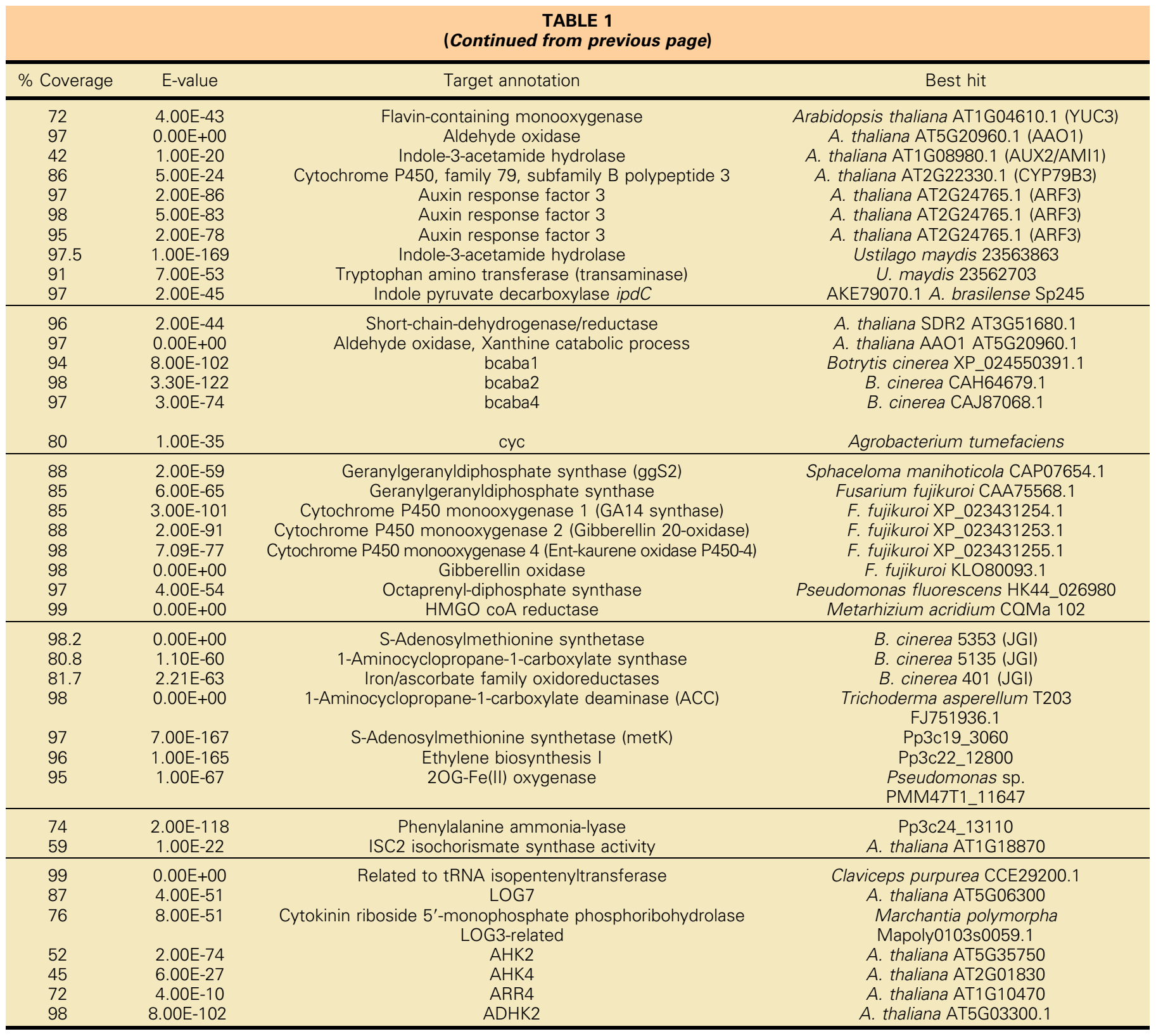


suggest that Trichoderma is capable of synthesizing these hormones, and that the production of CKs may be a characteristic shared with $C$. purpurea. There is evidence showing that various T. harzianum isolates reduce the total inactive CKs content in shoots of melon plants possibly due to the conversion of inactive to active CKs, which in conjunction with the effect of other phytohormones, such as IAA, ABA, and Et, the fungus uses to promote plant growth (Martínez-Medina et al. 2014). Given that we found genes that might be involved in CKs signaling, these compounds likely play a biological role in the fungus, such as hyphal branching, and may be involved in the Trichoderma-plant communication (Albrecht and Argueso 2017; Balmer et al. 2015; Shoresh et al. 2010).

Gibberellins (GAs). GAs are phytohormones that promote growth via the degradation of DELLA proteins, which repress growth (Sun 2011). They are known in fungi since their discovery in the 1920s in Gibberella fujikuroi, which causes foolish seedling disease and from which the name "gibberellins" is derived. GAs biological role in fungi is still not very clear, although these hormones are produced by several fungi, including Neurospora crassa (Chanclud and Morel 2016).
GAs biosynthesis in plants consists of a series of three steps: (i) biosynthesis of ent-kaurene from geranylgeranyldiphosphate (GGDP); (ii) conversion of ent-kaurene to $\mathrm{GA}_{12}$ via cytochrome $\mathrm{P} 450$ monooxygenase; and (iii) synthesis of $\mathrm{GA}_{19}$ and $\mathrm{GA}_{20}$ in the cytoplasm.

Recently, the similarities and convergence in the GAs biosynthetic pathway between plants, fungi, and bacteria have been reviewed by Salazar-Cerezo et al. (2018). In contrast with plants, in fungi the genes responsible for GAs biosynthesis are found in clusters: one GGDP synthase gene ( $g g s 2)$, the bifunctional entcopalyl diphosphate synthase/ent-kaurene synthase (cps/ks), one desaturase (2-oxoglutarate-dependent dioxygenase, DES, that converts $\mathrm{GA}_{4}$ to $\mathrm{GA}_{7}$ ) and three cytochrome $\mathrm{P} 450$ monooxygenases (P450-1, P450-2, and P450-3). Our bioinformatic survey of the T. atroviride genome allowed us to identify six genes, all related to GAs biosynthesis in F. fujikuroi, Sphaceloma manihoticola, Metarhizium acridium, or Pseudomonas fluorescens, with possible activities related to monooxygenases (IDs 293815 and 156885) geranylgeranyl pyrophosphate synthases (ID 160158), gibberellin oxidases (ID 302240), hydroxymethylglutaryl-CoA reductase (HmgR; ID 143946), and polyprenyl synthetases (ID 284926).

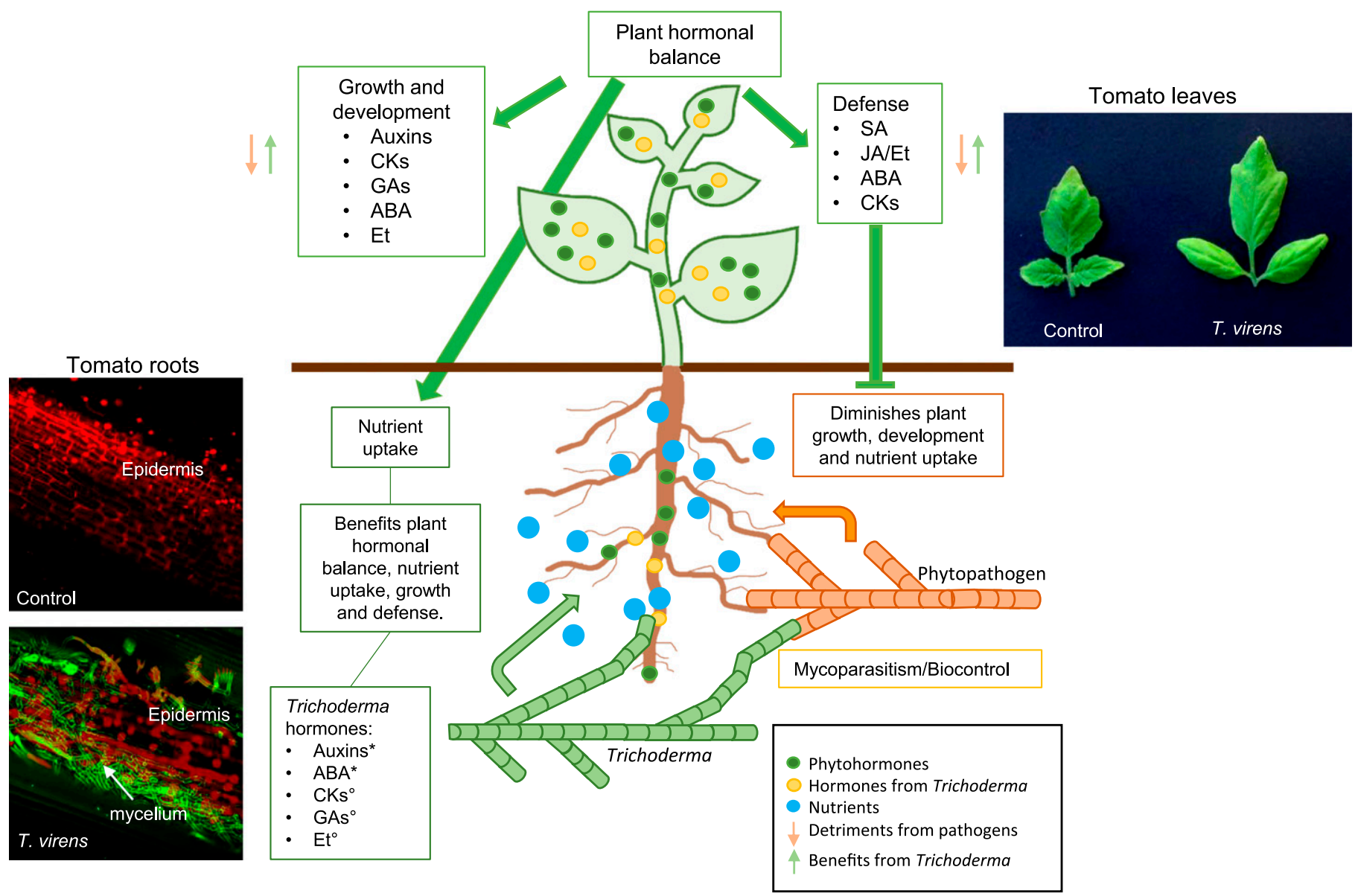

\section{FIGURE 2}

Trichoderma modifies plant hormonal balance. Plants cope with biotic and abiotic stresses by finely modulating a set of phytohormones that include auxins, cytokinins (CKs), gibberellins (GAs), abscisic acid (ABA), ethylene (Et), salicylic acid (SA), and jasmonic acid (JA) (green circles). This hormonal balance provides defense against pathogens, enables nutrient uptake (blue circles) from the soil, and allows proper growth and development of the plant (upper right image, tomato-control leaf). When faced with a pathogen (brown hyphae), the plant hormonal balance is compromised, and the result is a detriment to the overall plant health (brown arrows). Trichoderma has the potential to produce hormones $\left({ }^{\circ}\right)$, while there is evidence of the production of auxins and possibly ABA $\left({ }^{*}\right)$. When Trichoderma is present in the rhizosphere (green hyphae), it protects the plant by attacking phytopathogens, as a mycoparasite. Thus, when Trichoderma interacts with the plant, colonizing its roots (bottom left images), there is a modification in the hormonal balance of the plant, mediated by Trichoderma-derived hormones (yellow circles), improving plant health and vigor (small green arrows, upper right image, tomato- $T$. virens leaf). 
GAs are less studied in plant-microbe interactions, but their possible role may pose an interesting research subject. It is known that the degradation of DELLA proteins via GAs signaling releases the JA signaling repressor JAZ1, reducing JA-responsive gene expression (Hou et al. 2010), enhancing SA signaling and biotroph resistance (Pieterse et al. 2012). According to Salazar-Cerezo and coworkers (2018), GAs as secondary metabolites are not essential for fungal growth or development, but because their production occurs mainly when the fungi are exposed to a hostile environment, these compounds may have been advantageous for survival in their ecological niche. In F. fujikuroi, the presence of GAs is associated with the capacity of the fungus to infect rice plants (Wiemann et al. 2013), and the expression of the des gene in Solanum nigrum and $S$. dulcamara plants resulted in increased plant growth accompanied by a higher concentration of $\mathrm{GA}_{3}$ (Bhattacharya et al. 2012). Since we found in the Trichoderma genome 16 sequences related to DES activity, Trichoderma could promote plant growth by increasing the amount of GAs in the plant, in consequence augmenting plant biomass. There is also evidence that the endophytic fungus Penicillium foniculosum LHL06 secretes $\mathrm{GA}_{1}, \mathrm{GA}_{4}, \mathrm{GA}_{8}$, and $\mathrm{GA}_{9}$ under copper stress conditions, and the application of its culture medium, rich in bioactive GAs, to soybean plants reduced abiotic stress produced by copper (Khan and Lee 2013).

Although most of the enzymes required for GAs biosynthesis are encoded in the T. atroviride genome, we didn't find sequences coding for one of the key enzymes of the GAs biosynthesis pathway: the ent-copalyl diphosphate synthase/ent-kaurene synthase (cps/ks) which catalyze the intermediate steps of GAs biosynthesis (Albermann et al. 2013). Thus, it is unlikely that $T$. atroviride can produce GAs.

Ethylene. Ethylene is a gaseous phytohormone with roles in seed germination, fruit ripening and plant senescence (Bleecker and Kende 2000). Et also plays a role in plant immunity, affecting both the SA and the JA pathways (Pieterse et al. 2012). In plants, Et biosynthesis begins with S-adenosyl-L-methionine (S-AdoMet) and 1-aminocyclopropane-1-carboxylic acid (ACC) as precursors, and the main enzymes catalyzing this pathway are as follow: (i) SAdoMet synthetase (SAM), (ii) ACC synthase (ACS), and (iii) ACC oxidase (ACO) (Wang et al. 2002). Penicillium digitatum, $B$. cinerea, and $F$. oxysporum among other fungi are known to produce ethylene (Chanclud and Morel 2016; Tudzynski and Sharon 2002). In fungi, Et affects spore germination and hyphal growth. The biosynthetic pathway for Et is known in $B$. cinerea, which uses methionine as precursor of $\alpha$-keto $\gamma$-methylthiobutyric acid (KIMBA) to produce ethylene (Chague et al. 2002).

Our bioinformatic analyses indicated the presence of six genes in the T. atroviride genome that are related to Et biosynthesis in B. cinerea, T. asperellum, P. patens, or Pseudomonas sp. (Table 1). The genes putatively involved in Et biosynthesis encode an Sadenosylmethionine synthetase (ID 301763), a 1-aminocyclopropane1-carboxylate synthase (ID 297477), and member of the Iron/ascorbate family of oxidoreductases (ID 39146), suggesting that this fungus could have a functional ACC synthase pathway leading to the production of Et (Wang et al. 2002).

Et not only directly affects the physiology of the plant, but it is also related to nutrient stress. When the plant is subjected to nutrient limitation, there is an increase in the amount of ethylene, which results in enhanced auxin sensitivity and ethylene perception, leading to stress tolerance (Iqbal et al. 2013). One of the benefits of the interaction with Trichoderma for the plant is enhanced biotic and abiotic stress resistance (Mukherjee et al. 2013). The presence of genes related to Et biosynthesis in the genome of T. atroviride suggests that the production of this molecule by the fungus may be implicated in the plant tolerance to several types of stress.

Abscisic acid (ABA). ABA is a phytohormone that controls seed dormancy and development, stomatal aperture and promotes tolerance to abiotic stresses like drought and high salinity in plants (Hauser et al. 2011). In plant-pathogen interactions, ABA affects defense in a positive or negative manner, as reviewed by Asselbergh et al. (2008). ABA has a positive effect in the interaction between $A$. thaliana and $P$. syringae, or a negative one when interacting with Alternaria brassicicola, for example (Asselbergh et al. 2008). ABA can also affect SA-JA cross talk, regulating basal defenses, although, according to Flors et al. (2008), the molecular details are still poorly understood.

There is evidence of production of $\mathrm{ABA}$ by several fungi (Tudzynski and Sharon 2002; Chanclud and Morel 2016). The main role proposed for this fungal phytohormone is as a virulence factor promoting plant infection, as it has been shown to be involved in the M. oryzae-rice interaction (Jiang et al. 2010); and that accumulates at the early stages of the $U$. maydis-maize interaction (Morrison et al. 2015).

In $B$. cinerea, the biosynthetic pathway from isopentenyl diphosphate has been reported (Inomata et al. 2004), involving the genes bcaba1, bcaba2, bcaba3, and bcaba4 (Gong et al. 2014), homologs to the Arabidopsis atabal, ataba2, ataba3, and ataba4 genes that catalyzes the final steps of ABA biosynthesis (Dong et al. 2015). We identified six genes related to the ABA biosynthesis pathway (Table 1) of Arabidopsis, B. cinerea or Agrobacterium tumefaciens in the genome of T. atroviride, with putative xanthine oxidase/aldehyde oxidase (ID 141294) and short-chaindehydrogenase/reductase (ID 158420) functions, and homologs to the B. cinerea bcabal, bcaba2 and bcaba4 genes (IDs 80521, 295125 , and 28537, respectively), providing an almost complete ABA biosynthesis pathway. We did not find a homolog of bcaba3/ ataba3 in the $T$. atroviride genome. The enzyme encoded by this gene is key for the final step of ABA biosynthesis in A. thaliana, providing the necessary molybdenum cofactor to the AAO3 enzyme, which converts abscisic aldehyde to ABA (Dong et al. 2015). Without this gene, there is no production of active ABA. Our findings suggest that $T$. atroviride may not produce the active hormone but may be capable of producing the immediate precursor: abscisic aldehyde, which could be delivered into the plant during the interaction, where it could be transformed into ABA by the plant respective enzymes.

There is evidence suggesting that $T$. virens and $T$. atroviride are capable of modulating ABA in plants. Contreras-Cornejo et al. (2015) found that strains of both species are capable of modulating leaf transpiration and stomatal aperture in A. thaliana by inducing an ABA receptor. Thus, Trichoderma-derived ABA precursor could participate in regulating stomatal aperture in Arabidopsis, enhancing water stress tolerance in the plant. This would represent yet another mechanism through which Trichoderma could help counteract the effects of environmental stress on plants (Fig. 2).

\section{CONCLUSIONS}

The search for alternatives to chemical fertilizers and pesticides, in order to improve soil fertility and crop yield, led us to take a closer look at the interactions that take place in the rhizosphere. The global study of the microorganisms associated with plants, the plant microbiome, is gaining interest and has the potential to identify ways to obtain healthier crops and reduce or replace the use of agrochemicals. The diversity of the plant microbiome can greatly influence the general outcome of the plant growth and development (Etalo et al. 2018).

Fungi from the genus Trichoderma are well-known plant symbionts that exert a positive effect on plant growth, development, crop yield, and elicitation of plant defense responses through the modulation of plant hormonal mechanisms and production of several secondary metabolites (Hermosa et al. 2012; Van der Ent et al. 2009). In addition, these fungi are effective mycoparasites (Fig. 1) against plant pathogens and protect plants against them (Benítez et al. 2004). These characteristics make Trichoderma an excellent subject for exploration for its positive potential as an important part of the healthy plant holobiont. 
In recent years, manipulation of the plant microbiome has been proposed as a biocontrol strategy in the field. According to Berg et al. (2017), the use of organisms capable of modifying the plant microbiome structure and interactions will lead to the development of new "microbiome-based biocontrol strategies," helping the plants defend themselves against pathogens. The composition of the plant microbiome can lead to two important outcomes in agricultural fields: plant health, when the microbiome is diverse and there is a metabolic cooperation, nutrient and hormonal exchange between the plant host and microbiome; or plant disease, when the microbiome interacts with pathogens in a synergistic way, affecting overall plant health (Berg et al. 2017). The diversity of the microbiome is crucial to plant health and it can switch very easily from promoting plant health to promoting plant disease (Yan et al. 2017). In plant health, the organisms that are part of the microbiome influence nutrient and hormonal balance, leading to an increase in plant production. Plantbeneficial microbes like mycorrhizal fungi, nodule-forming bacteria, and plant endophytes are among the most influential organisms in the plant microbiome structure (Berg et al. 2017).

The mechanisms exerted by Trichoderma on the plant are diverse, from preventing phytopathogens from attacking the plant, to enhancing plant health and defenses. Recent studies raised the possibility that not only are effectors and secondary metabolites involved in the fungus-plant interaction, but fungal-derived hormones may have a role as well. One of the least explored mechanisms in the Trichoderma-plant interaction is the effect of fungal-derived hormones. Trichoderma produces auxins and an ABA precursor, and it may also produce CKs and Et that together may add to the plethora of ways in which this fungus interacts with its plant host, explaining many of the benefits reported as result of the Trichoderma-plant interaction.

The impact of the presence in the rhizosphere of Trichoderma on plants is summarized and represented in Figure 2, which highlights root colonization, leading to the increase in plant growth, protection against phytopathogens by mycoparasitism, and preparation against biotic and abiotic stressors through the participation of secondary metabolites, effectors, and the modulation of the hormonal balance.

\section{LITERATURE CITED}

Albermann, S., Linnemannstöns, P., and Tudzynski, B. 2013. Strategies for strain improvement in Fusarium fujikuroi: Overexpression and localization of key enzymes of the isoprenoid pathway and their impact on gibberellin biosynthesis. Appl. Microbiol. Biotechnol. 97:2979-2995.

Albrecht, T., and Argueso, C. T. 2017. Should I fight or should I grow now? The role of cytokinins in plant growth and immunity and in the growthdefence trade-off. Ann. Bot. 119:725-735.

Alonso-Ramírez, A., Poveda, J., Martín, I., Hermosa, R., Monte, E., and Nicolás, C. 2014. Salicylic acid prevents Trichoderma harzianum from entering the vascular system of roots. Mol. Plant Pathol. 15:823-831.

Asselbergh, B., De Vleesschauwer, D., and Höfte, M. 2008. Global switches and fine-tuning-ABA modulates plant pathogen defense. Mol. PlantMicrobe Interact. 21:709-719.

Atanasova, L., Le Crom, S., Gruber, S., Coulpier, F., Seidl-Seiboth, V., Kubicek, C. P., and Drizhinina, I. S. 2013. Comparative transcriptomics reveals different strategies of Trichoderma mycoparasitism. BMC Genomics $14: 121$

Balmer, A., Pastor, V., Gamir, J., Flors, V., and Mauch-Mani, B. 2015. The 'prime-ome': Towards a holistic approach to priming. Trends Plant Sci. 20: 443-452.

Barker, S. J., and Tagu, D. 2000. The roles of auxins and cytokinins in mycorrhizal symbioses. J. Plant Growth Regul. 19:144-154.

Beckers, G. J. M., Jaskiewicz, M., Liu, Y., Underwood, W. R., He, S. Y., Zhang, S., and Conrath, U. 2009. Mitogen-activated protein kinases 3 and 6 are required for full priming of stress responses in Arabidopsis thaliana. Plant Cell Online 21:944-953.

Behie, S. W., and Bidochka, M. J. 2014. Nutrient transfer in plant-fungal symbioses. Trends Plant Sci. 19:734-740.

Behie, S. W., Zelisko, P. M., and Bidochka, M. J. 2012. Endophytic insectparasitic fungi translocate nitrogen directly from insects to plants. Science 336:1576-1577.
Benítez, T., Rincón, A. M., Limón, M. C., and Codón, A. C. 2004. Biocontrol mechanisms of Trichoderma strains. Int. Microbiol. 7:249-260.

Berens, M. L., Berry, H. M., Mine, A., Argueso, C. T., and Tsuda, K. 2017. Evolution of hormone signaling networks in plant defense. Annu. Rev. Phytopathol. 55:401-425.

Berg, G., Köberl, M., Rybakova, D., Müller, H., Grosch, R., and Smalla, K. 2017. Plant microbial diversity is suggested as the key to future biocontrol and health trends. FEMS Microbiol. Ecol. 93:fix050.

Bhattacharya, A., Kourmpetli, S., Ward, D. A., Thomas, S. G., Gong, F., Powers, S. J., Carrera, E., Taylor, B., Nuñez de Caceres Gonzalez, F., Tudzynski, B., Phillips, A. L., Davey, M. R., and Hedden, P. 2012. Characterization of the fungal gibberellin desaturase as a 2-oxoglutaratedependent dioxygenase and its utilization for enhancing plant growth. Plant Physiol. 160:837-845.

Bleecker, A. B., and Kende, H. 2000. Ethylene: A gaseous signal molecule in plants. Annu. Rev. Cell Dev. Biol. 16:1-18.

Brotman, Y., Briff, E., Viterbo, A., and Chet, I. 2008. Role of swollenin, an expansin-like protein from Trichoderma, in plant root colonization. Plant Physiol. 147:779-789.

Cai, F., Yu, G., Wang, P., Wei, Z., Fu, L., Shen, Q., and Chen, W. 2013. Harzianolide, a novel plant growth regulator and systemic resistance elicitor from Trichoderma harzianum. Plant Physiol. Biochem. 73:106-113.

Carsolio, C., Gutiérrez, A., Jiménez, B., Van Montagu, M., and Herrera-Estrella, A. 1994. Characterization of ech-42, a Trichoderma harzianum endochitinase gene expressed during mycoparasitism. Proc. Natl. Acad. Sci. USA 91:10903-10907.

Chague, V., Elad, Y., Barakat, R., Tudzynski, P., and Sharon, A. 2002. Ethylene biosynthesis in Botrytis cinerea. FEMS Microbiol. Ecol. 40:143-149.

Chanclud, E., Kisiala, A., Emery, N. R. J., Chalvon, V., Ducasse, A., Romiti-Michel, C., Gravot, A., Kroj, T., and Morel, J.-B. 2016. Cytokinin production by the rice blast fungus is a pivotal requirement for full virulence. PLoS Pathog. 12:e1005457.

Chanclud, E., and Morel, J. B. 2016. Plant hormones: A fungal point of view. Mol. Plant Pathol. 17:1289-1297.

Chet, I., Harman, G. E., and Baker, R. 1981. Trichoderma hamatum: Its hyphal interactions with Rhizoctonia solani and Pythium spp. Microbiol. Ecol. 7:29-38.

Contreras-Cornejo, H. A., Macías-Rodríguez, L., Cortés-Penagos, C., and López-Bucio, J. 2009. Trichoderma virens, a plant beneficial fungus, enhances biomass production and promotes lateral root growth through an auxin-dependent mechanism in Arabidopsis. Plant Physiol. 149:1579-1592.

Contreras-Cornejo, H. A., Macías-Rodríguez, L., Vergara, A. G., and López-Bucio, J. 2015. Trichoderma modulates stomatal aperture and leaf transpiration through an abscisic acid-dependent mechanism in Arabidopsis. J. Plant Growth Regul. 34:425-432.

Cortes, C., Gutierrez, A., Olmedo, V., Inbar, J., Chet, I., and Herrera-Estrella, A. 1998. The expression of genes involved in parasitism by Trichoderma harzianum is triggered by a diffusible factor. Mol. Gen. Genet. 260: 218-225.

De Jonge, R., and Thomma, B. P. H. J. 2009. Fungal LysM effectors: Extinguishers of host immunity? Trends Microbiol. 17:151-157.

Djonovic, S., Vargas, W. A., Kolomiets, M. V., Horndeski, M., Wiest, A., and Kenerley, C. M. 2007. A proteinaceous elicitor Sm1 from the beneficial fungus Trichoderma virens is required for induced systemic resistance in maize. Plant Physiol. 145:875-889.

Dong, T., Park, Y., and Hwang, I. 2015. Abscisic acid: Biosynthesis, inactivation, homoeostasis and signalling. Essays Biochem. 58:29-48.

Druzhinina, I. S., Chenthamara, K., Zhang, J., Atanasova, L., Yang, D., Miao, Y., Rahimi, M. J., Grujic, M., Cai, F., Pourmehdi, S., Salim, K. A., Pretzer, C., Kopchinskiy, A. G., Henrissat, B., Kuo, A., Hundley, H., Wang, M., Aerts, A., Salamov, A., Lipzen, A., LaButti, K., Barry, K., Grigoriev, I. V., Shen, Q., and Kubicek, C. P. 2018. Massive lateral transfer of genes encoding plant cell wall-degrading enzymes to the mycoparasitic fungus Trichoderma from its plant-associated hosts ed. Francis Martin. PLOS Genet. 14:e1007322.

Elad, Y., Barak, R., and Chet, I. 1983. Possible role of lectins in mycoparasitism. J. Bacteriol. 154:1431-1435.

Etalo, D. W., Jeon, J. S., and Raaijmakers, J. M. 2018. Modulation of plant chemistry by beneficial root microbiota. Nat. Prod. Rep. 35:398-409.

Feraru, E., Vosolsobě, S., Feraru, M. I., Petrášek, J., and Kleine-Vehn, J. 2012. Evolution and structural diversification of PILS putative auxin carriers in plants. Front. Plant Sci. 3:227.

Finet, C., Berne-Dedieu, A., Scutt, C. P., and Marlétaz, F. 2013. Evolution of the ARF gene family in land plants: Old domains, new tricks. Mol. Biol. Evol. 30:45-56.

Flors, V., Ton, J., Van Doorn, R., Jakab, G., García-Agustín, P., and Mauch-Mani, B. 2008. Interplay between JA, SA and ABA signalling during basal and induced resistance against Pseudomonas syringae and Alternaria brassicicola. Plant J. 54:81-92. 
Freimoser, F. M., Hu, G., and St Leger, R. J. 2005. Variation in gene expression patterns as the insect pathogen Metarhizium anisopliae adapts to different host cuticles or nutrient deprivation in vitro. Microbiology 151: 361-371.

Gaderer, R., Lamdan, N., Frischmann, A., Sulyok, M., Krska, R., Horwitz, B. A., and Seidl-Seiboth, V. 2015. Sm2, a paralog of the Trichoderma cerato-platanin elicitor $\mathrm{Sm} 1$, is also highly important for plant protection conferred by the fungal-root interaction of Trichoderma with maize. BMC Microbiol. 15:2.

Garnica-Vergara, A., Barrera-Ortiz, S., Muñoz-Parra, E., Raya-González, J., Méndez-Bravo, A., Macías-Rodríguez, L., Ruiz-Herrera, L. F., and López-Bucio, J. 2016. The volatile 6-pentyl-2 H-pyran-2-one from Trichoderma atroviride regulates Arabidopsis thaliana root morphogenesis via auxin signaling and ETHYLENE INSENSITIVE 2 functioning. New Phytol. 209:1496-1512.

Genre, A., and Russo, G. 2016. Does a common pathway transduce symbiotic signals in plant-microbe interactions? Front. Plant Sci. 7:96.

Geremia, R. A., Goldman, G. H., Jacobs, D., Ardiles, W., Vila, S. B., Van Montagu, M., and Herrera-Estrella, A. 1993. Molecular characterization of the proteinase-encoding gene, $p r b 1$, related to mycoparasitism by Trichoderma harzianum. Mol. Microbiol. 8:603-613.

Gong, T., Shu, D., Yang, J., Ding, Z. T., and Tan, H. 2014. Sequencing and transcriptional analysis of the biosynthesis gene cluster of abscisic acidproducing Botrytis cinerea. Int. J. Mol. Sci. 15:17396-17410.

Guzmán-Guzmán, P., Alemán-Duarte, M. I., Delaye, L., Herrera-Estrella, A., and Olmedo-Monfil, V. 2017. Identification of effector-like proteins in Trichoderma spp. and role of a hydrophobin in the plant-fungus interaction and mycoparasitism. BMC Genet. 18:16.

Hassani, M. A., Durán, P., and Hacquard, S. 2018. Microbial interactions within the plant holobiont. Microbiome 6:58.

Hauser, F., Waadt, R., and Schroeder, J. I. 2011. Evolution of abscisic acid synthesis and signaling mechanisms. Curr. Biol. 21:R346-R355.

Hermosa, R., Viterbo, A., Chet, I., and Monte, E. 2012. Plant-beneficial effects of Trichoderma and of its genes. Microbiology 158:17-25.

Hinsch, J., Vrabka, J., Oeser, B., Novák, O., Galuszka, P., and Tudzynski, P. 2015. De novo biosynthesis of cytokinins in the biotrophic fungus Claviceps purpurea. Environ. Microbiol. 17:2935-2951.

Hirose, N., Takei, K., Kuroha, T., Kamada-Nobusada, T., Hayashi, H., and Sakakibara, H. 2008. Regulation of cytokinin biosynthesis, compartmentalization and translocation. J. Exp. Bot. 59:75-83.

Hou, X., Lee, L. Y. C., Xia, K., Yan, Y., and Yu, H. 2010. DELLAs modulate jasmonate signaling via competitive binding to JAZs. Dev. Cell 19:884-894.

Hoyos-Carvajal, L., Orduz, S., and Bissett, J. 2009. Growth stimulation in bean (Phaseolus vulgaris L.) by Trichoderma. Biol. Control 51:409-416.

Hu, G., and St. Leger, R. J. 2004. A phylogenomic approach to reconstructing the diversification of serine proteases in fungi. J. Evol. Biol. 17:1204-1214.

Igiehon, N. O., and Babalola, O. O. 2018. Rhizosphere microbiome modulators: Contributions of nitrogen fixing bacteria towards sustainable agriculture. Int. J. Environ. Res. Public Health 15:574.

Inomata, M., Hirai, N., Yoshida, R., and Ohigashi, H. 2004. The biosynthetic pathway to abscisic acid via ionylideneethane in the fungus Botrytis cinerea. Phytochemistry 65:2667-2678.

Iqbal, N., Trivellini, A., Masood, A., Ferrante, A., and Khan, N. A. 2013. Current understanding on ethylene signaling in plants: The influence of nutrient availability. Plant Physiol. Biochem. 73:128-138.

Jayaraman, D., Gilroy, S., and Ané, J.-M. 2014. Staying in touch: Mechanical signals in plant-microbe interactions. Curr. Opin. Plant Biol. 20:104-109.

Jiang, C.-J., Shimono, M., Sugano, S., Kojima, M., Yazawa, K., Yoshida, R., Inoue, H., Hayashi, N., Sakakibara, H., and Takatsuji, H. 2010. Abscisic acid interacts antagonistically with salicylic acid signaling pathway in riceMagnaporthe grisea interaction. Mol. Plant-Microbe Interact. 23:791-798.

Khan, A., and Lee, I.-J. 2013. Endophytic Penicillium funiculosum LHL06 secretes gibberellin that reprograms Glycine $\max \mathrm{L}$. growth during copper stress. BMC Plant Biol. 13:86.

Khan, A. L., Hamayun, M., Khan, S. A., Kang, S.-M., Shinwari, Z. K., Kamran, M., Rehman, S., Kim, J.-G., and Lee, I.-J. 2012. Pure culture of Metarhizium anisopliae LHL07 reprograms soybean to higher growth and mitigates salt stress. World J. Microbiol. Biotechnol. 28:1483-1494.

Kochar, M., Upadhyay, A., and Srivastava, S. 2011. Indole-3-acetic acid biosynthesis in the biocontrol strain Pseudomonas fluorescens Psd and plant growth regulation by hormone overexpression. Res. Microbiol. 162:426-435.

Křeček, P., Skůpa, P., Libus, J., Naramoto, S., Tejos, R., Friml, J., and Zažímalová, E. 2009. The PIN-FORMED (PIN) protein family of auxin transporters. Genome Biol. 10:249.

Kubicek, C. P., Herrera-Estrella, A., Seidl, V., Martinez, D. A., Druzhinina, I. S., Thons, M., Zeilinger, S., Casas-Flores, S., Horwitz, B. A., Mukherjee, P. K., Mukherjee, M., Kredics, L., Alcaraz, L. D., Aerts, A., Antal, Z., Atanasova, L., Cervantes-Badillo, M. G., Challacombe, J., Chertkov, O.,
McCluskey, K., Coulpier, F., Deshpande, N., von Döhren, H., Ebbole, D. J., Esquivel-Naranjo, E. U., Fekete, E., Flipphi, M., Glaser, F., Gómez-Rodríguez, E. Y., Gruber, S., Han, C., Henrissat, B., Hermosa, R., Hernández-Oñate, M., Karaffa, L., Kosti, I., Le Crom, S., Lindquist, E., Lucas, S., Lübeck, M., Lübeck, P. S., Margeot, A., Metz, B., Misra, M., Nevalainen, H., Omann, M., Packer, N., Perrone, G., Uresti-Rivera, E. E., Salamov, A., Schmoll, M., Seiboth, B., Shapiro, H., Sukno, S., Tamayo-Ramos, J. A., Tisch, D., Wiest, A., Wilkinson, H. H., Zhang, M., Coutinho, P. M., Kenerley, C. M., Monte, E., Baker, S. E., and Grigoriev, I. V. 2011. Comparative genome sequence analysis underscores mycoparasitism as the ancestral life style of Trichoderma. Genome Biol. 12:R40.

Kulkarni, R. D., Kelkar, H. S., and Dean, R. A. 2003. An eight-cysteinecontaining CFEM domain unique to a group of fungal membrane proteins. Trends Biochem. Sci. 28:118-121.

Lee, M.-Y., Shin, K.-H., Kim, Y.-K., Suh, J.-Y., Gu, Y.-Y., Kim, M.-R., Hur, Y.-S., Son, O., Kim, J.-S., Song, E., Lee, M.-S., Nam, K. H., Hwang, K. H., Sung, M.-K., Kim, H. J., Chun, J.-Y., Park, M., Ahn, T.-I., Hong, C. B., Lee, S.-H., Park, H. J., Park, J.-S., Verma, D. P. S., and Cheon, C.-I. 2005. Induction of thioredoxin is required for nodule development to reduce reactive oxygen species levels in soybean roots. Plant Physiol. 139: 1881-1889.

López-Bucio, J., Pelagio-Flores, R., and Herrera-Estrella, A. 2015. Trichoderma as biostimulant: Exploiting the multilevel properties of a plant beneficial fungus. Sci. Hortic. (Amsterdam) 196:109-123.

Malmierca, M. G., Barua, J., McCormick, S. P., Izquierdo-Bueno, I., Cardoza, R. E., Alexander, N. J., Hermosa, R., Collado, I. G., Monte, E., and Gutiérrez, S. 2015. Novel aspinolide production by Trichoderma arundinaceum with a potential role in Botrytis cinerea antagonistic activity and plant defense priming. Environ. Microbiol. 17:1103-1118.

Mano, Y., and Nemoto, K. 2012. The pathway of auxin biosynthesis in plants. J. Exp. Bot. 63:2853-2872.

Martínez-Medina, A., Del Mar Alguacil, M., Pascual, J. A., and Van Wees, S. C. M. 2014. Phytohormone profiles induced by Trichoderma isolates correspond with their biocontrol and plant growth-promoting activity on melon plants. J. Chem. Ecol. 40:804-815.

Mashiguchi, K., Tanaka, K., Sakai, T., Sugawara, S., Kawaide, H., Natsume, M., Hanadaa, A., Yaenoa, T., Shirasua, K., Yaod, H., McSteend, P., Zhaoe, Y., Hayashif, K.-i., Kamiyaa, Y., and Kas, H. 2011. The main auxin biosynthesis pathway in Arabidopsis. Proc. Natl. Acad. Sci. USA 108: $18512-18517$

Mathys, J., De Cremer, K., Timmermans, P., Van Kerckhove, S., Lievens, B., Vanhaecke, M., Cammue, B. P. A., and De Coninck, B. 2012. Genome-wide characterization of ISR induced in Arabidopsis thaliana by Trichoderma hamatum T382 against Botrytis cinerea infection. Front. Plant Sci. 3:108.

Mendoza-Mendoza, A., Zaid, R., Lawry, R., Hermosa, R., Monte, E., Horwitz, B. A., and Mukherjee, P. K. 2018. Molecular dialogues between Trichoderma and roots: Role of the fungal secretome. Fungal Biol. Rev. 32:62-85.

Morán-Diez, E., Rubio, B., Domínguez, S., Hermosa, R., Monte, E., and Nicolás, C. 2012. Transcriptomic response of Arabidopsis thaliana after $24 \mathrm{~h}$ incubation with the biocontrol fungus Trichoderma harzianum. J. Plant Physiol. 169:614-620.

Morrison, E. N., Emery, R. J. N., and Saville, B. J. 2015. Phytohormone involvement in the Ustilago maydis- Zea mays pathosystem: Relationships between abscisic acid and cytokinin levels and strain virulence in infected cob tissue. PLoS One 10:e0130945.

Mukherjee, P. K., Horwitz, B. A., Herrera-Estrella, A., Schmoll, M., and Kenerley, C. M. 2013. Trichoderma research in the genome era. Annu. Rev. Phytopathol. 51:105-129.

Müller, B., and Sheen, J. 2007. Advances in cytokinin signaling. Science 318: 68-69.

Nieto-Jacobo, M. F., Steyaert, J. M., Salazar-Badillo, F. B., Nguyen, D. V., Rostás, M., Braithwaite, M., De Souza, J. T., Jimenez-Bremont, J. F., Ohkura, M., Stewart, A., and Mendoza-Mendoza, A. 2017. Environmental growth conditions of Trichoderma spp. affects indole acetic acid derivatives, volatile organic compounds, and plant growth promotion. Front. Plant Sci. 8:102.

Nogueira-López, G., Greenwood, D. R., Middleditch, M., Winefield, C., Eaton, C., Steyaert, J. M., and Mendoza-Mendoza, A. 2018. The apoplastic secretome of Trichoderma virens during interaction with maize roots shows an inhibition of plant defence and scavenging oxidative stress secreted proteins. Front Plant Sci. 9:409.

Ortíz-Castro, R., Contreras-Cornejo, H. A., Macías-Rodrínguez, L., and López-Bucio, J. 2009. The role of microbial signals in plant growth and development. Plant Signal. Behav. 4:701-712.

Pieterse, C. M. J., Van der Does, D., Zamioudis, C., Leon-Reyes, A., and Van Wees, S. C. M. 2012. Hormonal modulation of plant immunity. Annu. Rev. Cell Dev. Biol. 28:489-521.

Plett, J. M., Daguerre, Y., Wittulsky, S., Vayssières, A., Deveau, A., Melton, S. J., Kohlera, A., Morrell-Falveyc, J. L., Bruna, A., Veneault-Fourreya, C., 
and Martin, F. 2014. Effector MiSSP7 of the mutualistic fungus Laccaria bicolor stabilizes the Populus JAZ6 protein and represses jasmonic acid (JA) responsive genes. Proc. Natl. Acad. Sci. USA 111:8299-8304.

Reineke, G., Heinze, B., Schirawski, J., Buettner, H., Kahmann, R., and Basse, C. W. 2008. Indole-3-acetic acid (IAA) biosynthesis in the smut fungus Ustilago maydis and its relevance for increased IAA levels in infected tissue and host tumour formation. Mol. Plant Pathol. 9:339-355.

Reithner, B., Ibarra-Laclette, E., Mach, R. L., and Herrera-Estrella, A. 2011. Identification of mycoparasitism-related genes in Trichoderma atroviride. Appl. Environ. Microbiol. 77:4361-4370.

Rivas, S., Rougon-Cardoso, A., Smoker, M., Schauser, L., Yoshioka, H., and Jones, J. D. G. 2004. CITRX thioredoxin interacts with the tomato Cf-9 resistance protein and negatively regulates defence. EMBO J. 23: 2156-2165.

Ruocco, M., Lanzuise, S., Lombardi, N., Woo, S. L., Vinale, F., Marra, R., Varlese, R., Manganiello, G., Pascale, A., Scala, V., Turrà, D., Scala, F., and Lorito, M. 2015. Multiple roles and effects of a novel Trichoderma hydrophobin. Mol. Plant-Microbe Interact. 28:167-179.

Salas-Marina, M. A., Isordia-Jasso, M. I., Islas-Osuna, M. A., Delgado-Sánchez, P., Jiménez-Bremont, J. F., Rodríguez-Kessler, M., Rosales-Saavedra, M. T., Herrera-Estrella, A., and Casas-Flores, S. 2015. The Epl1 and Sm1 proteins from Trichoderma atroviride and Trichoderma virens differentially modulate systemic disease resistance against different life style pathogens in Solanum lycopersicum. Front. Plant Sci. 6:77.

Salas-Marina, M. A., Silva-flores, M. A., Uresti-Rivera, E. E., Castro-longoria, E., Herrera-Estrella, A., and Casas-Flores, S. 2011. Colonization of Arabidopsis roots by Trichoderma atroviride promotes growth and enhances systemic disease resistance through jasmonic acid/ethylene and salicylic acid pathways. Eur. J. Plant Pathol. 131:15-26.

Salazar-Cerezo, S., Martínez-Montiel, N., García-Sánchez, J., Pérez-y-Terrón, R., and Martínez-Contreras, R. D. 2018. Gibberellin biosynthesis and metabolism: A convergent route for plants, fungi and bacteria. Microbiol. Res. 208:85-98.

Sasan, R. K., and Bidochka, M. J. 2013. Antagonism of the endophytic insect pathogenic fungus Metarhizium robertsii against the bean plant pathogen Fusarium solani f. sp. phaseoli. Can. J. Plant Pathol. 35:288-293.

Schirawski, J., and Perlin, M. 2018. Plant-Microbe Interaction 2017-The good, the bad and the diverse. Int. J. Mol. Sci. 19:1374.

Schirmbock, M., Lorito, M., Wang, Y. L., Hayes, C. K., Arisan-Atac, I., Scala, F., Harman, G. E., and Kubicek, C. P. 1994. Parallel formation and synergism of hydrolytic enzymes and peptaibol antibiotics, molecular mechanisms involved in the antagonistic action of Trichoderma harzianum against phytopathogenic fungi. Appl. Environ. Microbiol. 60:4364-4370.

Seidl, V., Song, L., Lindquist, E., Gruber, S., Koptchinskiy, A., Zeilinger, S., Schmoll, M., Martínez, P., Sun, J., Grigoriev, I., Herrera-Estrella, A., Baker, S. E., and Kubicek, C. P. 2009. Transcriptomic response of the mycoparasitic fungus Trichoderma atroviride to the presence of a fungal prey. BMC Genomics 10:567.
Seyfferth, C., and Tsuda, K. 2014. Salicylic acid signal transduction: The initiation of biosynthesis, perception and transcriptional reprogramming. Front. Plant Sci. 5:697.

Shoresh, M., Harman, G. E., and Mastouri, F. 2010. Induced systemic resistance and plant responses to fungal biocontrol agents. Annu. Rev. Phytopathol. 48:21-43.

Simm, S., Scharf, K. D., Jegadeesan, S., Chiusano, M. L., Firon, N., and Schleiff, E. 2016. Survey of genes involved in biosynthesis, transport, and signaling of phytohormones with focus on Solanum lycopersicum. Bioinform. Biol. Insights 10:185-207.

Stringlis, I. A., Zhang, H., Pieterse, C. M. J., Bolton, M. D., and de Jonge, R. 2018. Microbial small molecules-weapons of plant subversion. Nat. Prod. Rep. 35:410-433.

Sun, T. P. 2011. The molecular mechanism and evolution of the GA-GID1DELLA signaling module in plants. Curr. Biol. 21:R338-R345.

Tsavkelova, E., Oeser, B., Oren-Young, L., Israeli, M., Sasson, Y., Tudzynski, B., and Sharon, A. 2012. Identification and functional characterization of indole-3-acetamide-mediated IAA biosynthesis in plant-associated Fusarium species. Fungal Genet. Biol. 49:48-57.

Tudzynski, B., and Sharon, A. 2002. Biosynthesis, biological role and application of fungal phytohormones. Pages 183-211 in: Industrial Applications. H. D. Osiewacz, ed. Springer Berlin, Heidelberg.

Van der Ent, S., Van Wees, S. C. M., and Pieterse, C. M. J. 2009. Jasmonate signaling in plant interactions with resistance-inducing beneficial microbes. Phytochemistry 70:1581-1588.

Vázquez-Garcidueñas, S., Leal-Morales, C. A., and Herrera-Estrella, A. 1998. Analysis of the beta-1,3-glucanolytic system of the biocontrol agent Trichoderma harzianum. Appl. Environ. Microbiol. 64:1442-1446.

Wang, K. L., Li, H., and Ecker, J. R. 2002. Ethylene biosynthesis and signaling networks. Plant Cell 14:131-152.

Wiemann, P., Sieber, C. M. K., von Bargen, K. W., Studt, L., Niehaus, E. M., Espino, J. J., Huß, K., Michielse, C. B., Alberman, S., Wagner, D., Bergner, S. V., Connolly, L. R., Fischer, A., Reuter, G., Kleigrewe, K., Bald, T., Wingfield, B. D., Ophir, R., Freeman, S., Hippler, M., Smith, K. M., Brown, D. W., Proctor, R. H., Münsterkötter, M., Freitag, M., Humpf, H.-U., Güldener, U., and Tudzynski, B. 2013. Deciphering the cryptic genome: Genome-wide analyses of the rice pathogen Fusarium fujikuroi reveal complex regulation of secondary metabolism and novel metabolites. PLoS Pathog 9:e1003475.

Yan, Y., Kuramae, E. E., De Hollander, M., Klinkhamer, P. G. L., and Van Veen, J. A. 2017. Functional traits dominate the diversity-related selection of bacterial communities in the rhizosphere. ISME J. 11:56-66.

Zamioudis, C., and Pieterse, C. M. J. 2012. Modulation of host immunity by beneficial microbes. Mol. Plant-Microbe Interact. 25:139-150.

Živanović, B. D., Ullrich, K. K., Steffens, B., Spasić, S. Z., and Galland, P. 2018. The effect of auxin (indole-3-acetic acid) on the growth rate and tropism of the sporangiophore of Phycomyces blakesleeanus and identification of auxin-related genes. Protoplasma 255:1331-1347. 